\title{
REVIEWS
}

\section{Recurrent Aphthous Stomatitis} - a Reflection of Gastrointestinal Diseases?

\section{Afty nawracające jako objaw chorób przewodu pokarmowego}

\author{
Department of General Dentistry, Medical University of Lodz, Łódz, Poland
}

\begin{abstract}
Recurrent oral ulceration is a common condition accompanied by pain which often interferes with food intake and speaking. A variety of etiological factors can contribute to oral ulceration, e.g. local factors, such as trauma or viral infection, or systemic diseases that manifest in the oral cavity. Recurrent aphthous stomatitis (RAS) is one of the most frequently diagnosed condition characterized by repeated appearance of oral ulcers. Clinical features of RAS are not homogenous (different ulcer types, different severity of the disease), and the etiology is unclear. No objective criteria are known for definitive RAS diagnosis, and descriptive criteria are not well-defined. The majority of RAS cases are believed to be idiopathic, but some can be associated with an underlying systemic diseases, including nutritional deficiencies and inflammatory conditions. RAS is relatively often described to be associated with inflammatory diseases of gastrointestinal tract, and sometimes oral manifestation precedes gastrointestinal symptoms. Therefore, dentists might help to diagnose a range of systemic diseases.

In the present review, the literature on most commonly RAS-associated conditions, inflammatory diseases associated with gastrointestinal tract, has been analyzed, providing practical tips helping to differentiate between idiopathic RAS and RAS accompanying systemic disease, and to facilitate adequate ulcer management (Dent. Med. Probl. 2015, 52, 4, 472-478).
\end{abstract}

Key words: gastrointestinal diseases, recurrent aphthous stomatitis, oral ulcers.

Słowa kluczowe: afty nawracające, zamiany nadżerkowe i owrzodzenia jamy ustnej, choroby przewodu pokarmowego.

Oral ulcers are common manifestations of many local or general disorders. Ulceration is the most common lesion of the oral mucosa and the differential diagnosis can be complex. Any oral ulcer is frequently labeled as 'aphtha', which can be harmful, as it may delay the diagnosis of a range of systemic diseases. Recurrent aphthous stomatitis (RAS) is a common condition, characterized by symptoms of periodic painful single or multiple oral ulcers. The prevalence of RAS varies from $5 \%$ to $25 \%$ in the general population, depending on the methodology and population studied $[1,2]$. Although RAS is the most common disease affecting the oral mucosa, its etiology and pathogenesis remain unclear. Many studies have been conducted to uncover the nature of RAS, but the results were often contradictory or nondefinitive.

For many years RAS has been described as idiopathic or associated with systemic disorders. The majority of RAS cases are believed to be idiopath- ic, but some can be associated with an underlying systemic diseases, including hematinic deficiencies (iron, vitamins $\mathrm{B}_{1}, \mathrm{~B}_{2}, \mathrm{~B}_{6}, \mathrm{~B}_{12}$, folic acid, and zinc), diseases of the gastrointestinal tract (celiac disease, Crohn's disease, ulcerative colitis, H. pylori infection), immune disorders (HIV/AIDS, cyclic neutropenia), autoinflammatory diseases (Behcet's disease, MAGIC syndrome, Sweet's syndrome, PFAPA, Reiter's syndrome). This secondary form of RAS is also called 'RAS-like ulcers' [3]. However, it is still controversial which oral ulcers associated with these systemic conditions are truly RAS and which are oral ulcers similar to RAS.

\section{Clinical Diagnosis of RAS}

The diagnosis of RAS is based on clinical findings. RAS is historically divided into major, minor or herpetiform type according to the criteria de- 
scribed by Lehner [4]. This classification of RAS complicates proper diagnosis even more, because these three clinical presentations could be manifestations of one disease, or represent a spectrum of oral manifestations of different diseases [5]. As for minor and major aphthous ulcers, there is a general agreement that they belong to the same entity, herpetiform RAS is considered sometimes as a different disease [6]. There are many reports showing the early onset of minor and major aphthous lesions and their simultaneous appearance in the oral cavity (Fig. 1), while herpetiform RAS seems to be a rare disease with the highest prevalence in the fourth decade of life $[2,4,7]$. These three forms of RAS differ not only in size, but also in mode of healing and predilection to certain regions in the oral cavity. While minor RAS lesions heal spontaneously without scarring, major and herpetiform lesions are characterized by prolonged healing that might result in scarring. Major and herpetiform RAS can occur on non-keratinized but also keratinized mucosa, and herpetiform RAS often occur on ventral surface of tongue and floor of the mouth [8]. Lehner [4] originally described herpetiform RAS as lesions showing the features of recurrent intraoral herpetic infection (ulcers preceding by intraepithelial vesicles, location on masticatory mucosa, presence of intracellular bodies in the keratinocytes), and until
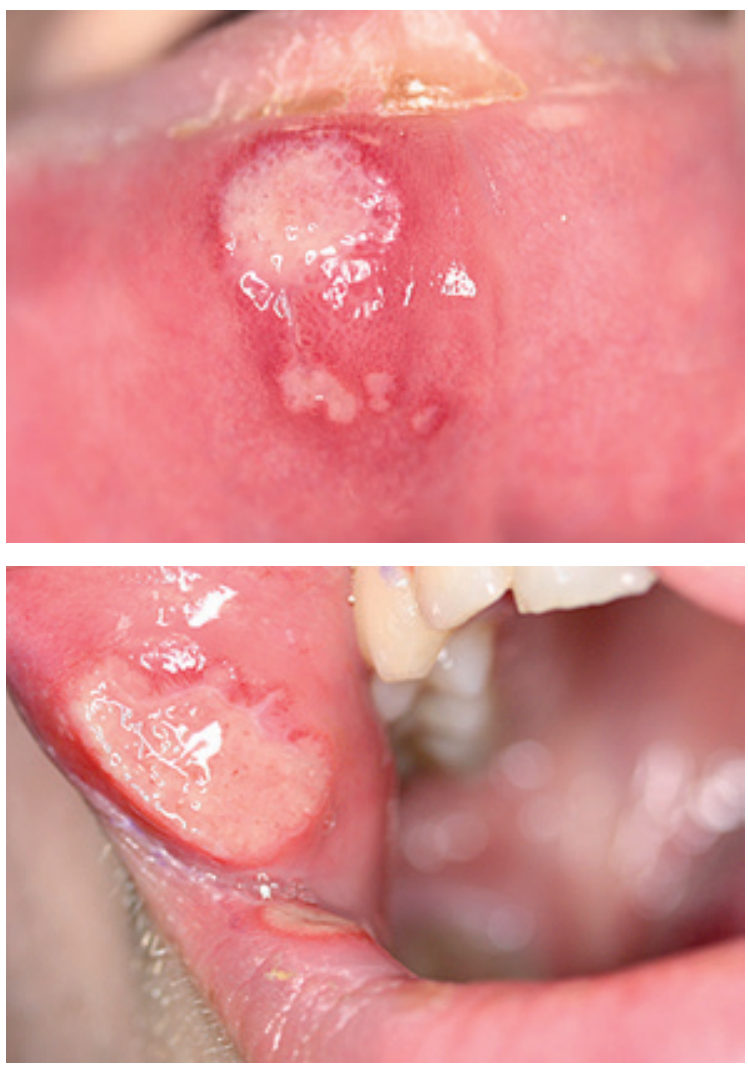

Fig. 1. Coappearance of major and minor aphthous ulcers on the labial mucosa now we cannot fully disregard the viral etiology for herpetiform RAS.

Minor RAS is the most common form affecting about $80-85 \%$ of all RAS cases, thus the majority of literature on RAS describes the minor form. In 2004 Natah et al. [9] systemized the extensive literature available on RAS and proposed the inclusion criteria for minor RAS. They proposed that a diagnosis of idiopathic RAS and secondary RAS (associated with systemic diseases) is established when four major and one minor criteria are fulfilled [9]. Recently, a new definition of RAS has been proposed, emphasizing the spontaneous emergence of more than two bouts of oral ulcers per year, not associated with ulcers elsewhere in the body or with any underlying systemic abnormality [10]. This short definition implies that only idiopathic RAS is a true form of RAS. For the clinician, it is crucial to distinguish localized RAS from ulcers caused by an underlying systemic disorder, as the correct diagnosis determines adequate treatment.

\section{RAS and Gastrointestinal Diseases}

The diseases of the gastrointestinal tract are commonly associated with RAS. It makes sense, because the mouth is considered to be the initial part of gastrointestinal tract and the doorway to the gut. Dentists can play an important role in identifying people who may have unrecognized gastrointestinal disease. Appropriate referral and a timely diagnosis can help prevent serious complications of these diseases.

\section{Celiac Disease}

Celiac disease (gluten sensitive enteropathy) is a common disorder affecting both children and adults. Many people with celiac disease do not present the classic malabsorptive syndrome, which results in diagnosis delay. Population-based serologic studies estimate that $1 \%$ of North Americans may have celiac disease, and about $90 \%$ of these cases remain undiagnosed [11]. Dental enamel defects and recurrent aphthous ulcers may be the only manifestation of this disorder. Interestingly, in some cases, oral ulcers can be the first sign of celiac disease. Several authors have reported cases where patients presenting recurrent oral ulceration were subsequently diagnosed with celiac disease [12-14]. Oral ulcers associated with celiac disease have been described to resemble the characteristic of minor RAS, with an average size 
of $5 \mathrm{~mm}$ and a typical mucosal distribution [15]. However, the majority of the studies reporting associations between RAS and celiac disease did not report any well-defined criteria for RAS diagnosis, while the diagnosis of celiac disease was usually well supported by biopsy and/or antibody tests. In a large survey of a Canadian population with biopsy-proven celiac disease, $16 \%$ of children ( $<16$ years of age) and $26 \%$ of adults reported having recurrent oral ulcers $[16,17]$. Overall, the literature proves the association between oral ulcers and celiac disease; however, these oral ulcers may not be RAS. This conclusion is further supported by the data showing that oral ulcers that are a manifestation of celiac disease respond to a gluten-free diet, while classical RAS does not. As the majority of celiac disease cases are asymptomatic, it is crucial for dentists encounter recurrent oral ulcers to enquire about other clinical symptoms, associated disorders and family history of celiac disease. In suspected cases, patients should be advised to perform serologic screening for celiac disease and, if positive, confirm the diagnosis by intestinal biopsy [18].

\section{Inflammatory Bowel Diseases}

Aphthous-like ulceration can be an extraintestinal manifestation of inflammatory bowel diseases (IBD) like Crohn's disease and ulcerative colitis [19]. This ulceration usually occurs with increased intestinal disease activity $[20,21]$. Approximately $10-30 \%$ of patients with IBD have oral mucosal ulcers, and the oral manifestation occasionally precedes intestinal symptoms [22-24]. In general, oral ulcers are more common in Crohn's disease compared to ulcerative colitis, and more prevalent in children compared to adults [25]. Oral ulcers, a cobblestone appearance of the oral mucosa and coexisting edema of the lips are well-documented symptoms of orofacial Crohn's disease (Fig. 2) [26-28]. Aphthous lesions are typically located on the labial and buccal mucosa but may also affect the tongue and oropharynx. Nonspecific oral ulcers usually resemble minor RAS, but specific Crohn lesions often have indurated borders and are histologically different because of the granulomatous nature of the lesion. Pyostomatitis vegetans is a rare manifestation of IBD characterized by multiple pustules and erosions anywhere on the oral mucosa (Fig. 3) [29, 30]. The histology shows epithelial acanthosis and superficial ulceration. The underlying connective tissue exhibits neutrophil and eosinophil infiltration, with miliary
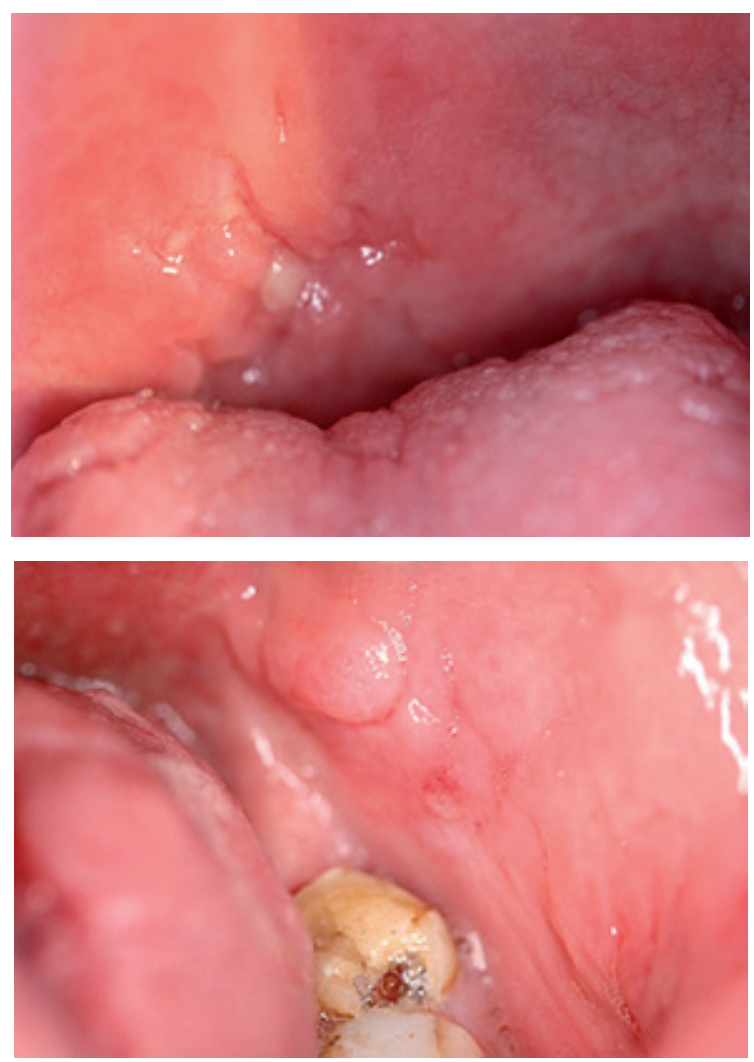

Fig. 2. Atypical ulcers and a cobblestone appearance of the soft palate and buccal mucosa in the patient with Crohn's disease
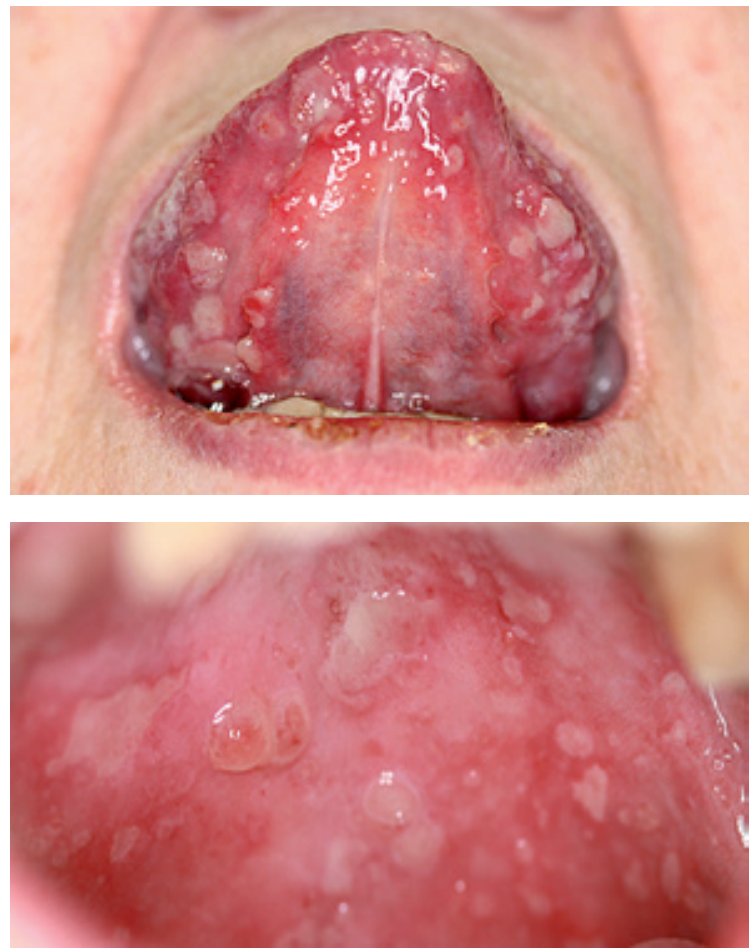

Fig. 3. Pyostomatitis vegetans in the tongue and palatal mucosa of the patient with ulcerative colitis

abscesses in some cases [31]. There is a controversy about the nature of IBD-associated oral ulcers. The pathogenesis involve inadequate local 
immune response, defects in mechanisms of oral tolerance, imbalance in oral microbiota [25]. U1cers may also reflect associated hematinic deficiencies [32]. Current guidelines recommend that any patient with recurrent or persistent oral ulcers should be considered for endoscopy, especially when concomitant bowel symptoms and/ or highly specific type of oral lesions are present [25]. Peripheral blood examination as well as anti-Saccharomyces cerevisiae antibody (ASCA) and perinuclear anti-neutrophil cytoplasmic antibody (p-ACNA) levels may be helpful [33].

\section{Helicobacter pylori Infection}

Oral cavity is the major extragastric reservoir of Helicobacter pylori, and a close relation between infection in the oral cavity and stomach has been shown [34-36]. Considering the histological similarities between gastric and oral ulcers, possible involvement of this organism in the development of RAS has been suggested. The acidic environment of the oral cavity and the warm temperature near $37^{\circ} \mathrm{C}$ in dental plaque offers an ideal medium for the growth of $H$. pylori. Some studies indicated that $H$. pylori is associated with RAS [37-42]. Recent meta-analysis showed a greater rate of $H$. pylori infection in RAS patients compared with control subjects [43]. However, only $29.5 \%$ of RAS patients and $19.93 \%$ of healthy controls were $H$. pylori-positive, while $70.5 \%$ RAS patients and $80.07 \%$ of controls were $H$. pylori-negative. The differences between RAS and healthy group were not great, but statistically significant [43]. The possible mechanism contributing to the development of oral ulcers in the presence of $H$. pylori is not clear. In peptic ulceration, $H$. pylori induces lymphocyte chemotactic factors, which cause neutrophilic infiltration and mucosal injury. Aphthous ulcers, however, are primarily induced by cytotoxic activity of T lymphocytes, and neutrophils seem not to be directly involved in RAS pathogenesis [44, 45]. Another possible explanation has been recently proposed that $H$. pylori-associated gastric disease is often accompanied by iron and vitamin $\mathrm{B}_{12}$ deficiency which, in turn, promote oral ulceration. $H$. pylori eradication contributes to the return to normal hematological values and decrease in RAS severity $[46,47]$. Collectively, based on the published data, $H$. pylori does not play a causative role in RAS, as these bacteria are identified in similar proportions both in RAS and non-RAS individuals. However, H. pylori infection-associated iron and vitamin $\mathrm{B}_{12}$ deficiency can be the secondary cause of recurrent oral ulcers. According to current guidelines, for detection of $H$. pylori infection in RAS patients asymptomatic for gastrointestinal tract, noninvasive tests are recommended (urea breath test, stool antigen detection), while endoscopy-based assay is recommended if endoscopy is indicated [48].

\section{Practical Approach to the Diagnosis of Underlying Gastrointestinal Diseases in Patients with RAS}

The onset of RAS is the highest between the ages of 10 and 19 years and becomes less frequent with advancing age [49]. When the severity and frequency of the episodes of ulcers is high, or if RAS begins or significantly increases in severity before 10 years of age or after the third decade, it should increase suspicion that the cause of the condition may be attributed to an underlying systemic disease. A focused history and examination are, therefore, crucial in order to reach a working differential diagnosis (Table 1). Inquire about clinical symptoms of gastrointestinal diseases, including abdominal pain, diarrhea, weight loss, poor growth, anemia and extreme fatigue. Remember that the absence of these symptoms does not rule out the presence of these diseases. Inquire about celiac disease and inflammatory bowel diseases during family history screening. Having a firstor second-degree relative with these diseases increases the likelihood of a positive diagnosis. Inquire about the presence of other autoimmune diseases, especially type 1 diabetes and thyroiditis, as the presence of these diseases will further increase the probability of celiac disease. Based on the available literature, simplified protocol can be applied to determine whether the patient presents with idiopathic form of RAS or RAS-like ulcers as

Table 1. Important features to be noted from history and examination in patients with recurrent oral ulcers

\begin{tabular}{|l|l|}
\hline History & Examination \\
\hline Family history & $\begin{array}{l}\text { Site of ulcers (nonkeratini- } \\
\text { zed or keratinized mucosa) }\end{array}$ \\
\hline $\begin{array}{l}\text { Onset, frequency, dura- } \\
\text { tion of ulceration }\end{array}$ & Size and shape of ulcers \\
\hline $\begin{array}{l}\text { Associated medical con- } \\
\text { ditions }\end{array}$ & Number of ulcers \\
\hline Genital, skin lesions & Base of ulcers \\
\hline $\begin{array}{l}\text { Gastrointestinal distur- } \\
\text { bances }\end{array}$ & Surrounding tissues \\
\hline Treatment history & \\
\hline
\end{tabular}


Table 2. Simplified protocol for idiopathic RAS diagnosis

\begin{tabular}{|l|l|}
\hline Inclusion criteria & Exclusion criteria \\
\hline $\begin{array}{l}\text { Regular round or oval } \\
\text { shape, erythematous halo }\end{array}$ & Atypical ulcers \\
\hline $\begin{array}{l}\text { Presence on nonkeratini- } \\
\text { zed oral mucosa }\end{array}$ & $\begin{array}{l}\text { Presence on keratinized } \\
\text { oral mucosa }\end{array}$ \\
\hline Pain & Ulcers in extraoral location \\
\hline Spontaneous healing & Lack of pain \\
\hline $\begin{array}{l}\text { Onset in childhood or } \\
\text { adolescence }\end{array}$ & Persistent ulcers \\
\hline $\begin{array}{l}\text { Absence of systemic fe- } \\
\text { atures }\end{array}$ & Onset in adults \\
\hline $\begin{array}{l}\text { Normal hematological } \\
\text { results }\end{array}$ & Systemic complains \\
\hline & $\begin{array}{l}\text { Abnormal hematological } \\
\text { results }\end{array}$ \\
\hline
\end{tabular}

a manifestation of systemic disease (Table 2). To support the findings from patient's history and examination, additional diagnostic test should be performed.

\section{Diagnostic Tests}

Hematological tests: Full blood count, iron, ferritin, folate, total iron-binding capacity, B vitamins, zinc, magnesium [50].

Serological test: IgA anti-endomysial antibodies, IgA and IgG tissue transglutaminase antibodies and total IgA level are currently recommended screening tests for celiac disease. ASCA and p-ACNA levels are helpful in diagnostics of inflammatory bowel diseases $[18,33]$.

Histology: There is rarely a need to biopsy ulcers, but unusual lesions might warrant this, especially where there is a suspicion of granulomatous or inflammatory conditions, such as Crohn's disease or ulcerative colitis [25].

Endoscopy: An endoscopy of the upper and lower gastrointestinal tract together with mucosa biopsy should be considered for confirmation of celiac disease, inflammatory bowel disease or H. pylori infection [25, 48].

\section{Conclusions}

RAS is a common disease affecting children and young adults. Although the majority of RAS cases are idiopathic with self-limiting character, in some patients unrecognized underlying systemic disease might be present. A focused history and examination are critical to avoid misdiagnosis of other types of recurrent oral ulcers as RAS. Any unusual clinical findings, such as sudden onset of recurrent ulcers, atypical appearance of ulcers, unusual predilection to certain location or any additional systemic complains should alarm the dentist to consider other possible diagnosis. Very close attention should be especially paid to children, as timely recognition of celiac disease will prevent many systemic complications.

\section{References}

[1] Rogers R.S.: Recurrent aphthous stomatitis: clinical characteristics and associated systemic disorders. Semin. Cutan Med. Surg. 1997, 16, 278-283.

[2] Scully C., Porter S.: Oral mucosal disease: recurrent aphthous stomatitis. Br. J. Oral Maxillofac. Surg. 2008, 46, 198-206.

[3] Scully C.: Clinical practice: Aphthous ulceration. N Engl. J. Med. 2006, 355, 165-172.

[4] Lehner T.: Autoimmunity in oral diseases, with special reference to recurrent oral ulceration. Proc. R Soc. Med. 1968, 61, 515-24.

[5] Scully C., Porter S.: Recurrent aphthous stomatitis: Current concepts of etiology, pathogenesis and management. J. Oral Pathol. Med. 1989, 18, 21-7.

[6] Porter S.R., Scully C., Pedersen A.: Recurrent aphthous stomatitis. Crit. Rev. Oral Biol. Med. 1998, 9, 306-21.

[7] Scully C., Gorsky M., LozadA-Nur F.: The diagnosis and management of recurrent phthous stomatitis: a consensus approach. J. Am. Dent. Assoc. 2003, 134, 200-207.

[8] Shashy R.G., Ridley M.B.: Aphthous ulcers: A difficult clinical entity. Am. J. Otolaryngol. 2000, 21, 389-93.

[9] Natah S.S., Konttinen Y.T., Enattah N.S., Ashammakhi N., Sharkey K.A., Häyrinen-Immonen R.: Recurrent aphthous ulcers today: A review of growing knowledge. Int. J. Oral Maxillofac. Surg. 2004, 33, 221-34.

[10] Tappuni A.R., Kovacevic T., Shirlaw P.J., Challacombe S.J.: Clinical assessment of disease severity in recurrent aphthous stomatitis. J. Oral Pathol. Med. 2013, 42, 635-641.

[11] Hill I., Dirks M., Liptak G.S., Colletti R.B., Fasano A., Guandalini S.: Guideline for the diagnosis and treatment of celiac disease in children: recommendations of the North American Society for Pediatric Gastroenterology, Hepatology and Nutrition. J. Pediatr. Gastroenterol. Nutr. 2005, 40, 1-19.

[12] Veloso F.T., Saleiro J.V.: Small-bowel changes in recurrent ulceration of the mouth. Hepatogastroenterol. 1987, $34,36-37$.

[13] Jokinen J., Peters U., Maki M., Miettinen A., Collin P.: Celiac sprue in patients with chronic oral mucosal symptoms. J. Clin. Gastroenterol. 1998, 26, 23-26. 
[14] Olszewska M., Sulej J., Kotowski B.: Frequency and prognostic value of IgA and IgG endomysial antibodies in recurrent aphthous stomatitis. Acta Derm. Venereol. 2006, 86, 332-334.

[15] Ferguson M.M., Wray D., Carmichael H.A., Russell R.I., Lee F.D.: Coeliac disease associated with recurrent aphthae. Gut, 1980, 21, 223-226.

[16] Cranney A., Zarkadas M., Graham I.D., Butzner J.D., Rashid M., Warren R.: The Canadian Celiac Health Survey. Dig. Dis. Sci. 2007, 52, 1087-1095.

[17] Rashid M., Cranney A., Zarkadas M., Graham I.D., Switzer C., Case S.: Celiac disease: evaluation of the diagnosis and dietary compliance in Canadian children. Pediatrics 2005, 116, 754-759.

[18] Rashid M., Zarkadas M., Anca A., Limeback H.: Oral manifestations of celiac disease: a clinical guide for dentists. J. Can. Dent. Assoc. 2011, 77, 1-6.

[19] Vavricka S.R., Schoepfer A., Scharl M., Lakatos P.L., Navarini A., Rogler G.: Extraintestinal manifestations of inflammatory bowel disease. Inflamm. Bowel Dis. 2015, 21, 1982-1992.

[20] Su C.G., Judge T.A., Lichtenstein G.R.: Extraintestinal manifestations of inflammatory bowel disease. Gastroenterol. Clin. North Am. 2002, 31, 307-327.

[21] Vavricka S.R., Brun L., Ballabeni P.: Frequency and risk factors for extraintestinal manifestations in the Swiss inflammatory bowel disease cohort. Am. J. Gastroenterol. 2011, 106, 110-119.

[22] Greenstein A.J., Janowitz H.D., Sachar D.B.: The extra-intestinal complications of Crohn's disease and ulcerative colitis: a study of 700 patients. Medicine, 1976, 55, 401-412.

[23] Halme L., Meurman J.H., Laine P.: Oral findings in patients with active or inactive Crohn's disease. Oral Surg. Oral Med. Oral Pathol. 1993, 76, 175-181.

[24] Vavricka S.R., Rogler G., Gantenbein C., Spoerri M., Prinz Vavricka M., Navarini A.A., French L.E., Safroneeva E., Fournier N., Straumann A., Froehlich F., Fried M., Michetti P., Seibold F., Lakatos P.L., Peyrin-Biroulet L., Schoepfer A.M.: Chronological order of appearance of extraintestinal manifestations relative to the time of IBD diagnosis in the Swiss inflammatory bowel disease cohort. Inflamm. Bowel Dis. 2015, 21, 1794-1800.

[25] Katsanos K.H., Torres J., Roda G., Brygo A., Delaporte E., Colombel J.F.: Review article: non-malignant oral manifestations in inflammatory bowel diseases. Aliment. Pharmacol. Ther. 2015, 42, 40-60.

[26] Simpson H.E., Summersgill G.B., Howell R.A.: Oral lesions in Crohn's disease. J. Oral. Med. 1976, 31, 67-68.

[27] Snyder M.B., Cawson R.A.: Oral changes in Crohn's disease. J. Oral Surg. 1976, 34, 594-599.

[28] Weiss J.S., Gupta A.K., Regezi J., Rasmussen J.E.: Oral ulcers and cobblestone plaques. Oral Crohn's disease (CD). Arch. Dermatol. 1991, 127, 889-892.

[29] Femiano F., Lanza A., Buonaiuto C., Perillo L., Dell'Ermo A., Cirillo N.: Pyostomatitis vegetans: a review of the literature. Med. Oral Patol. Oral Cir. Bucal 2009, 14, 114-117.

[30] Ruiz-Roca J.A., Berini-Aytés L., Gay-Escoda C.: Pyostomatitis vegetans. Report of two cases and review of the literature. Oral Surg. Oral Med. Oral Pathol. Oral Radiol. Endod. 2005, 99, 447-454.

[31] Thornhill M.H., Zakrzewska J.M., Gilkes J.J.H.: Pyostomatitis vegetans: report of three cases and review of the literature. J. Oral Pathol. Med. 1992, 21, 128-133.

[32] Massironi S., Rossi R.E., Cavalcoli F.A., Della Valle S., Fraquelli M., Conte D.: Nutritional deficiencies in inflammatory bowel disease: therapeutic approaches. Clin. Nutr. 2013, 32, 904-910.

[33] Lemberg D.A., Day A.S.: Crohn disease and ulcerative colitis in children: an update for 2014. J. Paediatr. Child Health, 2015, 51, 266-270.

[34] Al Asqah M., Al Hamoudi N., Anil S., Al Jebreen A., Al-Hamoudi W.K.: Is the presence of Helicobacter pylori in the dental plaque of patients with chronic periodontitis a risk factor for gastric infection? Can. J. Gastroenterol. 2009, 23, 177-179.

[35] Eskandari A., Mahmoudpour A., Abolfazli N., Lafzi A.: Detection of Helicobacter pylori using PCR in dental plaque of patients with and without gastritis. Med. Oral Patol. Oral Cir. Bucal 2010, 15, $28-31$.

[36] Assumpção M.B., Martins L.C., Melo Barbosa H.P., Barile K.A., De Almeida S.S., Assumpção P.P.: Helicobacter pylori in dental plaque and stomach of patients from Northern Brazil. World J. Gastroenterol. 2010, 16, 3033-3039.

[37] Birek C., Grandhi R., McNeill K., Singer D., Ficarra G., Bowden G.: Detection of Helicobacter pylori in oral aphthous ulcers. J. Oral Pathol. Med. 1999, 28,197-203.

[38] Karaca S., Seyhan M., Senol M., Harputluoglu M.M., Ozcan A.: The effects of gastric Helicobacter pylori eradication on recurrent aphthous stomatitis. Int. J. Dermatol. 2008, 47, 615-617.

[39] Shimoyama T., Horie N., Kato T., Kaneko T., Komiyama K.: Helicobacter pylori in oral ulcerations. J. Oral Sci. 2000, 42, 225-229.

[40] Taş D.A., YAKar T., SAKalli H., Serin E.: Impact of Helicobacter pylori on the clinical course of recurrent aphthous stomatitis. J. Oral Pathol. Med. 2013, 42, 89-94.

[41] Albanidou-Farmaki E., Giannoulis L., Markopoulos A., Fotiades S., Aggouridaki X., Farmakis K., Papanayotou P.: Outcome following treatment for Helicobacter pylori in patients with recurrent aphthous stomatitis. Oral Dis. 2005, 11, 22-26.

[42] Long B.J., Chen K., Wu B.L., DuAn J.M.: Detection of Helicobacter pylori in oral cavity of patients with recurrent aphthous ulcer. J. South Med. Univ. 2007, 27, 477-478.

[43] Li L., Gu H., Zhang G.: Association between recurrent aphthous stomatitis and Helicobacter pylori infection: a meta-analysis. Clin. Oral Invest. 2014, 18, 1553-1560. 
[44] Lewkowicz N., Kurnatowska A.J., Lewkowicz P., Banasik M., Tchórzewski H.: Peripheral blood neutrophils in pathogenesis of recurrent aphthous ulcers. Dent. Med. Probl. 2002, 39, 69-77 [in Polish].

[45] Lewkowicz N., Kur B., Kurnatowska A., Tchorzewski H., Lewkowicz P.: Expression of Th1/Th2/Th3/Th17related genes in recurrent aphthous ulcers. Arch. Immunol. Ther. Exp. 2011, 59, 399-406.

[46] Taş D.A., Yakar T., Sakalli H., Serin E.: Impact of Helicobacter pylori on the clinical course of recurrent aphthous stomatitis. J. Oral Pathol. Med. 2013, 42, 89-94.

[47] Adler I., Muiño A., Aguas S., Harada L., Diaz M., Lence A., Labbrozzi M., Muiño J.M., Elsner B., Avagnina A., Denninghoff V.: Helicobacter pylori and oral pathology: relationship with the gastric infection. World J. Gastroenterol. 2014, 20, 9922-9935.

[48] Talley N.J., Vakil N.: Practice Parameters Committee of the American College of Gastroenterology. Guidelines for the management of dyspepsia. Am. J. Gastroenterol. 2005, 100, 2324-2337.

[49] Chattopadhyay A., Chatterjee S.: Risk indicators for recurrent aphthous ulcers among adults in the US. Community Dent. Oral Epidemiol. 2007, 35, 152-159.

[50] Porter S.R., Kingsmill V., Scully C.: Audit of diagnosis and investigations in patients with recurrent aphthous stomatitis. Oral Surg. Oral Med. Oral Pathol. 1993, 76, 449-452.

\section{Address for correspondence:}

Natalia Lewkowicz

Department of General Dentistry

Medical University of Lodz

Pomorska 251

92-213 Łódź

Poland

Tel.: 426757540

E-mail: natalia.lewkowicz@umed.lodz.pl

Conflict of Interest: None declared

Received: 28.08.2015

Revised: 13.09.2015

Accepted: 28.09.2015 